\title{
Determine the unmet need for family planning in a hilly area in a state of North India
}

\author{
Nidhi Chauhan ${ }^{1}$, Saurabh $\operatorname{Rattan}^{2 *}$
}

\author{
${ }^{1}$ Programme Officer, National Health Mission, Shimla, Himachal Pradesh, India \\ ${ }^{2}$ Programme Officer, District Kangra, Himachal Pradesh, India
}

Received: 08 April 2021

Accepted: 06 May 2021

\author{
*Correspondence: \\ Dr. Saurabh Rattan, \\ E-mail: drsaurabhrattan@gmail.com
}

Copyright: (c) the author(s), publisher and licensee Medip Academy. This is an open-access article distributed under the terms of the Creative Commons Attribution Non-Commercial License, which permits unrestricted non-commercial use, distribution, and reproduction in any medium, provided the original work is properly cited.

\begin{abstract}
Background: The utilization of family planning services has improved over the decade, but still the SDG's health target to ensure universal access to sexual and reproductive health care services is yet to be achieved, unmet need being one of the imperative component.

Methods: A cross-sectional study was undertaken in the rural field practice area of Department of Community Medicine, Indira Gandhi Medical College, Shimla, Himachal Pradesh, India, from July 2018 to June 2019. Total sample size calculated was 316. Random sampling was used to select eligible couple to whom a predesigned, pretested, semi-structured and anonymous interview schedule was administered after taking consent.

Results: The mean age of the participants was 30.2 \pm 6.1 years. The modern contraceptive prevalence rate (mCPR) was found to be $67.7 \%$ among women of reproductive age group (15-49 years). Male condom (36\%), followed by female sterilisation $(30 \%)$ were the most common methods preferred. Unmet need of family planning was found to be $10.4 \%$.

Conclusions: Besides male condoms and female sterilisation, other methods of contraception were adopted by meagre number of women. Though, the unmet need for family planning was lesser in this study, still, efforts are needed to plunge it, for ameliorating the contraceptive prevalence rate. Also, the availability of basket of contraceptive choices in government sector need sheer assiduity.
\end{abstract}

Keywords: Family planning, Prevalence study, Reproductive age, Unmet need

\section{INTRODUCTION}

As per World Health Organisation, women with unmet need are those who are fecund and sexually active but are not using any method of contraception, and not wanting any more children or wanting to delay the next child. The notion of unmet need points to the breach between women's reproductive intentions and their contraceptive behaviour. ${ }^{1}$

The contraceptives are used in almost all regions of the world by majority of the women of reproductive age group (15-49 years). In 2017, 63\% of these women were using some form of contraception. More than one in ten married or in-union women worldwide have an unmet need for family planning; meaning thereby, that they want to stop or delay childbearing but are not using any method of contraception to prevent the same. The unmet need for family planning is projected to remain above 10 $\%$ worldwide between now and 2030 despite the reductions anticipated for some regions. ${ }^{2}$

In 2019 worldwide, among the 1.9 billion women of reproductive age group, 1.1 billion have a need for family planning; of these, 842 million are using contraceptive methods, and 270 million have an unmet need for contraception. As per Sustainable Development Goals (SDG) indicator 3.7.1, the proportion of the need for family planning satisfied by modern methods, was $75.7 \%$ 
globally in 2019, yet less than half of the need for family planning was met in Middle and Western Africa. ${ }^{3,4}$

Family planning is an important tool to meet people's reproductive health and fertility needs and has been at the precedence of political and programmatic interventions in India as well as globally. Unmet need can be disaggregated into unmet need for limiting births and unmet need for spacing births. As per NFHS 4 survey, unmet need for spacing methods was $5.6 \%$ and $7.2 \%$ for limiting methods. The overall unmet need was highest in Manipur (30.1\%), Nagaland (22.3\%) and Sikkim $(21.7 \%)$, and lowest in Andhra Pradesh (4.6\%), Punjab $(4.6 \%)$ and Chandigarh $(6.2 \%) .^{5}$ Reducing the unmet need could be one of the best ways to curtail the number of unplanned births, induced abortions, maternal deaths and DALYs. It has been estimated that meeting women's unmet needs for modern contraceptives would prevent about one quarter to one-third of all maternal deaths, thereby saving 140,000 to 150,000 lives per year. ${ }^{6,7}$

In the state of Himachal Pradesh, $16 \%$ of currently married women have an unmet need for family planning (NFHS 4 survey), substantially higher than the $8 \%$ in NFHS- $3 .^{8}$

India's family planning programme, despite its numerous successes, has had to grapple with misconceptions, lack of information regarding the contraceptives available, and a continuing rift in public perception on the importance and need for family planning. There has also been recognition about the prevailing unmet need for family planning, which is an obstacle to women's realisation of their optimal reproductive health and fertility needs. ${ }^{9}$

The endeavour needs to be directed towards fulfilling the unmet need for contraception by counselling and ensuring the availability of modern contraceptive methods to such women.

With this backdrop in mind, the present study intents to estimate the unmet need of family planning in hilly terrain area of state of North India.

\section{METHODS}

\section{Study design}

A Community based descriptive cross-sectional study.

\section{Study setting and participants}

The study was done among women of reproductive age group (15-49 years) in the rural field practise area of Department of Community Medicine, Indira Gandhi Medical College \& Hospital, Shimla.

\section{Study period}

One year (July 2018 to June 2019)

\section{Sample size}

In a population of 3030 , nearly 500 will be eligible couples $(15-17 \%)$. Considering contraceptive prevalence rate of 54\% (NFHS-4), with 5\% margin of error and $99 \%$ confidence limits, and a non-response rate of $10 \%$ a sample of 313 was calculated. Total sample taken is 316 .

\section{Inclusion criteria}

To become eligible for enrolment a participant should be:

Resident of the area (residing for $>6$ months). Ever married females (15-49 years). Consented to participate in study.

\section{Exclusion criteria}

Chronic serious/debilitating patient, Any psychiatric illness.

\section{Study tool}

A predesigned, pretested, semi-structured and anonymous interview schedule was used for the study purpose.

\section{Sampling strategy}

A sampling framework was prepared from eligible couple register maintained at Rural Training Health centre. The representative sample was selected randomly from the eligible couple register maintained at rural training health centre. The selected subjects were then approached for data collection.

\section{Statistical analysis}

Data was collected and entered in Microsoft excel spread sheet, cleaned for errors and analysed using Epi info version 7.2.1.0 software. To summarize the demographic data, descriptive statistics were used. Frequencies, percentages and their $95 \%$ confidence intervals were used to describe categorical variables. Mean and standard deviations were calculated for continuous variables. Pearson Chi-square and Fischer Exact test was used for univariate association analysis. A two-sided p- value of $<0.05$ was considered as statistically significant.

\section{Ethical considerations}

Informed consent was taken from all the participants after explaining the purpose of study. Confidentiality and anonymity of the participants was ensured. All the participants were counselled \& communicated about FP services available for them. The participants were apprised regarding the consequences of not using contraceptive methods. Exposure variables: Sociodemographic variables like age, type of family, education of participants and their spouse, occupation, socioeconomic status. 
Outcome variables: Current use of any family planning method and unmet need for family planning.

\section{RESULTS}

The mean age of 316 participants interviewed was $30.2 \pm$ 6.1 years ranging from 19-48 years. Majority of the participants $(70.2 \%)$ were aged less than 30 years and $46.2 \%$ of the participants belonged to upper middle class, according to modified BG Prasad Scale based on consumer price index of July 2018. Table 1 shows the demographic profile of the study participants.

Table 1: Distribution of study participants according to socio-demographic characteristics $(\mathrm{N}=316)$.

\begin{tabular}{|ll|}
\hline Socio Demographic Variables & N $(\%)$ \\
\hline Age groups (years) & \\
\hline $15-25$ & $70(22.2)$ \\
\hline $26-35$ & $190(60.1)$ \\
\hline $36-49$ & $56(17.7)$ \\
\hline Parity & \\
\hline 0 & $54(17.1)$ \\
\hline 1 & $109(34.5)$ \\
\hline 2 & $125(39.5)$ \\
\hline 3 & $20(6.3)$ \\
\hline$\geq 4$ & $8(2.5)$ \\
\hline Educational Status & \\
\hline Illiterate & $12(3.8)$ \\
\hline$\leq$ High School & $188(59.5)$ \\
\hline$>$ High School & $116(36.7)$ \\
\hline Educational Status of Spouse & \\
\hline Illiterate & $5(1.6)$ \\
\hline$\leq$ High School & $151(47.8)$ \\
\hline$>$ High School & $160(50.6)$ \\
\hline Occupation & \\
\hline Working & $82(25.9)$ \\
\hline Agricultural worker & $63(19.9)$ \\
\hline Home-maker & $171(54.1)$ \\
\hline *Socio-Economic Class & \\
\hline Upper class & $121(38.3)$ \\
\hline Upper middle class & $146(46.2)$ \\
\hline Middle class & $29(9.2)$ \\
\hline Lower middle class & $11(3.5)$ \\
\hline Lower class & $9(2.8)$ \\
\hline Soio-Econ Cla & \\
\hline
\end{tabular}

*Socio-Economic Class: as per BG Prasad classification

Of all the participants, $90 \%$ were aware of one or the other available family planning methods. Modern contraceptive prevalence rate (mCPR) was found to be $67.7 \%$ among women of reproductive age group and was more $(57.3 \%)$ among females aged more than 30 years.

The most common method of contraception used was male condom (36\%), followed by female sterilization (30\%). The reasons for not using any contraceptive method by the woman of reproductive age groups has been summarised in Table 2.
Table 2: Reasons for not using any contraceptive method among non-pregnant $(\mathrm{N}=316)$.

\begin{tabular}{|ll|}
\hline Reasons & N (\%) \\
\hline Fertility related & \\
\hline Wants more children & $43(13.6)$ \\
\hline Hysterectomy done & $3(1)$ \\
\hline Opposition to use & $4(1.3)$ \\
\hline Husband opposed & \\
\hline Lack of knowledge & $20(6.3)$ \\
\hline Knows no method & $1(0.3)$ \\
\hline Knows no source & $17(5.4)$ \\
\hline Method related & $1(0.3)$ \\
\hline Fear of side-effects & $1(0.32)$ \\
\hline Inconvenient to use & \\
\hline Lack of access (too far) & $1(0.32)$ \\
\hline \begin{tabular}{l} 
Other \\
\hline $\begin{array}{l}\text { Husband working at different place due } \\
\text { to work }\end{array}$
\end{tabular} \\
\hline
\end{tabular}

Unmet need of family planning was found to be $10.4 \%$. And if this unmet need of family planning is taken care of, then the contraceptive prevalence rate would rise to nearly $70 \%$ from $67.7 \%$. The demand for family planning i.e. the unmet need and current user of any contraceptive method, among currently married women in reproductive age group was found to be $78.1 \%$. (Figure 1 ).

On univariate analysis, it was found that the utilisation of family planning methods among married females was found to increase with the education status of both the participants and their spouses ( $p$ value of $<0.001$ ). The socio-demographic variables that were found to be statistically associated with the unmet need of family planning were age, education of the female and socioeconomic status of the family. (Table 3 ).

Table 3: Socio-demographic correlates of unmet need of family planning $(\mathrm{N}=316)$.

\begin{tabular}{|c|c|c|}
\hline Characteristics & $\mathbf{N}(\%)$ & P value \\
\hline \multicolumn{3}{|c|}{ Age groups (years) } \\
\hline $15-25$ & $18(56.2)$ & \multirow[b]{3}{*}{$*<0.001$} \\
\hline $26-35$ & $11(9)$ & \\
\hline $36-46$ & $4(7.4)$ & \\
\hline \multicolumn{3}{|l|}{ Education } \\
\hline Illiterate & $1(16.7)$ & \multirow[b]{3}{*}{$*<0.001$} \\
\hline$\leq$ High School & $31(26.5)$ & \\
\hline$>$ High School & $1(1.2)$ & \\
\hline \multicolumn{3}{|c|}{ Socio-economic status } \\
\hline Upper class & $3(3.2)$ & \multirow{4}{*}{$*<0.001$} \\
\hline $\begin{array}{l}\text { Upper Middle } \\
\text { class }\end{array}$ & $24(27)$ & \\
\hline Middle class & $3(23.1)$ & \\
\hline $\begin{array}{l}\text { Lower middle } \\
\text { class }\end{array}$ & $3(30)$ & \\
\hline
\end{tabular}

$* \mathrm{P}<0.005$ considered statistically significant 


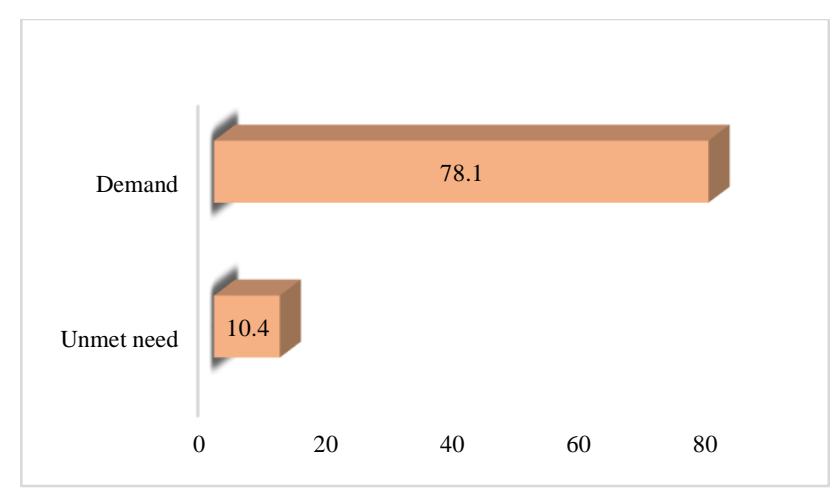

Figure 1: Percent distribution of currently married women age 15-49 by need for family planning.

\section{DISCUSSION}

The ability of women to live through the reproductive years and beyond, with reproductive choice, dignity and successful child bearing, and to be free from gynaecological diseases and risks is reproductive health. ${ }^{10}$

The present study found that $91.5 \%$ of currently married women aged 15-49 years knew at least one method of contraception. Of them $67.7 \%$ of the participants were currently using one or the other method of contraception. The most common method of contraception was male condom (37\%), followed by female sterilisation (30\%). $40 \%$ of the modern contraceptives were obtained from government health institutes.

The findings nearly corroborated with that of the study conducted in rural Madhya Pradesh, where it was found that $70.9 \%$ were using contraceptives, with female sterilization being the most common method preferred (36\%), followed by male condoms (6\%) and pills (4\%). ${ }^{11}$

As per NFHS 4 survey, $99 \%$ of currently married women aged 15-49 knew at least one method of contraception. Overall, the contraceptive prevalence rate (CPR) was found to be $54 \%$ among currently married women (15-49 years). Almost seven in 10 (69\%) modern method contraceptive users obtained their method from the public health sector.

The unmet need for family planning in our study came out to be $10.4 \%$. If this unmet need is met, then the contraceptive prevalence rate would increase to $70.3 \%$ from $67.7 \%$.

A study done by Sahasrabuddhe et al, found that unmet need for family planning was $23 \%$, which was in contrast to our study. ${ }^{11}$ Our study findings corroborated with NFHS-4 survey, that found $13 \%$ of currently married women have an unmet need for family planning. If all currently married women who want to space or limit their children were to use a family planning method, the contraceptive prevalence rate would increase from $54 \%$ to $66 \%$.
The variables found to be significantly associated with the use of any modern contraceptive method were higher education of females and their spouses. $90 \%$ of the women utilising family planning methods were found in the age group of 26 to 35 years.

In contrast, a study in Gorakhpur on determinants of contraceptive use among eligible couples revealed that the maximum (36\%) contraception use was seen in the women of age group 35-39 years of age and minimum $(7.1 \%)$ use was seen in $45-49$ years. ${ }^{12}$ Pal et al in their study on urban slums of Lucknow found that maximum use $(75.0 \%)$ of contraception was seen in the age group 40-44 years. ${ }^{13}$

The difference in the finding with present study may be because of higher literacy status and more awareness about contraceptive use for spacing and early use of contraceptive methods.

The contraceptive use was found to be significantly associated with the education of the participant, education of their spouses and those belonging to middle class.

The total unmet need for family planning decreased after the age of 35 years or more. It was in concordance with a study done at Burundi on determinants of unmet need of family planning, that showed that the likelihood of total unmet need $(32.4 \%)$ decreased with age after $35+$, compared to women aged $15-24 .{ }^{14}$

The possible reasons for the variations might be due to the expanding health services coverage and increased awareness of family planning and maternal health services in the study area.

\section{CONCLUSION}

To conclude, in our study the overall reproductive health profile of ever married females was satisfactory. Regarding family planning utilisation, it was found that the male condoms and female sterilisation were the main methods of contraception, that were preferred.

Other methods of contraception were adopted by meager number of women. Though, the unmet need for family planning was lesser in this study, still, efforts are needed to plunge it, for ameliorating the contraceptive prevalence rate.

\section{ACKNOWLEDGMENTS}

Authors would like to acknowledge the participants for their constant support in conducting the study.

Funding: No funding sources Conflict of interest: None declared

Ethical approval: The study was approved by the Institutional Ethics Committee 


\section{REFERENCES}

1. WHO Sexual \& Reproductive Health; Unmet need for Family Planning. Available at: https://www.who.int/reproductivehealth/topics/famil y_planning/unmet_need_fp. Accessed on $12^{\text {th }}$ March 2021.

2. United Nations, Department of Economic and Social Affairs, Population Division (2017). World Family Planning 2017 - Highlights (ST/ESA/SER.A/414). Available https://www.un.org/development/desa/pd/sites. Accessed on $12^{\text {th }}$ March 2021.

3. Kantorová V, Wheldon MC, Ueffing P, Dasgupta ANZ. Estimating progress towards meeting women's contraceptive needs in 185 countries: A Bayesian hierarchical modelling study. PLoS Med. 2020; 17(2):e1003026.

4. United Nations, Department of Economic and Social Affairs, Population Division. Family Planning and the 2030 Agenda for Sustainable Development. New York: United Nations. Available at: https://www.un.org/en/development/desa/population/ publications/pdf/family/familyPlanning_DataBooklet 2019.pdf. Accessed on $12^{\text {th }}$ March 2021 .

5. International Institute for Population Sciences (IIPS) and ICF. 2017. National Family Health Survey (NFHS-4), 2015-16: India. Mumbai: IIPS.

6. Singh S. "Adding It Up: The Benefits of Investing in Sexual and Reproductive Health Care". New York: Alan Guttmacher Institute. 2003.

7. Collumbien M. "Non-use and use of ineffective methods of contraception". In: Ezzati M, Lopez AD, Rodgers A, Murray CJL, eds. "Comparative Quantification of Health Risks: Global and Regional
Burden of Disease Attributable to Selected Major Risk Factors". Geneva: WHO. 2004:1255-320.

8. State Fact Sheet Himachal Pradesh: National Family Health Survey-4(2015-16) Ministry of Health and Family Welfare, Government of India. Available at: rchiips.org/NFHS/pdf/NFHS4/HP_FactSheet.pdf. Accessed on $12^{\text {th }}$ March 2021.

9. Population Foundation of India; Meeting the unmet need- A choice based approach to Family Planning. Available at https://populationfoundation.in/wpcontent/uploads/2020/09/Choice-Based-FP-WhitePaper.pdf. Accessed on $12^{\text {th }}$ March 2021.

10. Reproductive Rights are Human Rights; A Handbook for National Human Rights Institutions, United Nation Population Fund. Available at: https://www.ohchr.org/documents/publications/nhrih andbook.pdf. Accessed on 20th May 2021.

11. Sahasrabuddhe A, Kori S, Arora VK, Bute J. A study to assess unmet need for family planning and contraceptive choices among married women of reproductive age in rural Madhya Pradesh. Int $\mathbf{J}$ Community Med Public Health. 2018;5:4725-30.

12. Hasan A, Nandeshwar AA, Srivastava DK, Khan A. A study on prevalence of contraceptive use and its determinants among eligible couples in urban slums of Gorakhpur district. Int J Community Med Public Health. 2018;5:4288-91.

13. Pal A, Mohan U, Idris MZ, Masood J. Factors affecting unmet need for family planning in married women of reproductive age group in urban slums of Lucknow. Ind J Comm Health. 26:44-9.

14. Nzokirishaka A, Itua I. Determinants of unmet need for family planning among married women of reproductive age in Burundi: a cross-sectional study. Contracept Reprod Med. 2018; 3:11.

Cite this article as: Chauhan N, Rattan S. Determine the unmet need for family planning in a hilly area in a state of North India. Int J Reprod Contracept Obstet Gynecol 2021;10:2234-8. 